\title{
A literatura da Shoah no Brasil: o frágil corpo humano em A morte de um carrasco, de Joseph Nichthauser
}

\author{
The Shoah literatura in Brazil: the fragile human body in Joseph Nichthauser
}

\section{Lizandro Carlos Calegari}

Universidade Federal de Santa Maria - UFSM - Santa Maria - Rio Grande do Sul - Brasil

\begin{abstract}
Resumo: No século XX, com a Primeira e Segunda Guerras Mundiais, viu-se o surgimento de um novo homem. Trata-se de um homem não mais dotado de forças heroicas capazes de resistir à violência dos novos tempos, mas de um homem fragilizado, vulnerável e debilitado. Esse sentimento de impotência tomou conta principalmente daqueles que foram vítimas dos regimes autoritários e totalitários. No contexto internacional, particularmente, após a Segunda Guerra, muitos judeus, devido à dizimação por que passaram e à violência que sofreram, saíram da Europa em busca de uma vida menos indigna em outros países do mundo. O judeu brasileiro Joseph Nichthauser é um exemplo de sobrevivente da Shoah nazista. Vítima da fome, das perdas irreparáveis, das doenças e dos trabalhos forçados, viu na escrita um meio para encontrar e atribuir um sentido para sua vida. Em 1972, publica Quero viver... memórias de um ex-morto, e, em 2003, lança $A$ morte de um carrasco. O objetivo deste trabalho é analisar a violência e a opressão exercidas sobre os corpos dos judeus nos campos de concentração, a animalização a que eram submetidos, a desautorização de suas crenças religiosas e o próprio processo de imigração por que passaram, tendo como base o segundo livro publicado pelo autor. A reflexão sobre esses itens é importante porque permite a construção de uma nova ética, um novo ponto de vista para se pensar a humanidade, as relações humanas e as minorias. Para o embasamento desta proposta, buscou-se respaldo em autores como Elaine Scarry e Walter Benjamin.
\end{abstract}

Palavras-chave: Shoah, judeus, Joseph Nichthauser, violência.

Abstract: In the $X X^{\text {th }}$ century, with the First and the Second World Wars, there was the emergence of a new man. A man no longer endowed with heroic forces capable of resisting the violence of the new times, but a weakened and vulnerable man. This feeling of disability has taken hold mainly of those who were victim of authoritarian and totalitarian regimes. In the international context, particularly after The Second World War, many Jews, due to decimation and violence suffered, left Europe in search of a less unworthy life in other countries of the world. The Brazilian Jew Joseph Nichthauser is an example of a survivor of the Nazi Shoah. Victim of hunger, irreparable loss, disease, and forced labor, he saw in writing a means to find and assign meaning to his life. In 1972, he published Quero Viver... Memórias de um ExMorto, and, in 2003, A Morte de um Carrasco. This paper aims at analyzing violence and oppression exerted on the Jews' bodies in concentration camps, the animalization to which they were subjected, the disallowance of their religious beliefs, and the immigration process they went through, based on the second book published by the author. A reflection on these items is important because they allow the construction of a new ethics, a new point of view to think about humanity, human relations, and minorities. Elaine Scarry and Walter Benjamin are the main authors who underscore the present approach.

Keywords: Shoah, jews, Joseph Nichthauser, violence. 
Em um célebre ensaio publicado em 1933, intitulado "Experiência e pobreza", Walter Benjamin menciona alguns efeitos da Primeira Guerra Mundial, fazendo referência ao saldo negativo que o aludido evento teria trazido à humanidade. Dentre essas consequências, o crítico cita a pobreza de experiência, a fome, o sentimento de abandono, o constante risco de destruição e o iminente impacto de forças violentas e antagônicas sobre o ser humano. Ao se referir a esse indivíduo que atravessou um período de profundo mal-estar, o pensador alemão é sábio na escolha das palavras que o adjetivam: ele vai falar em "frágil e minúsculo corpo humano" (BENJAMIN, 1985, p. 115). Não se trata, aqui, portanto, de um sujeito íntegro e dotados de atitudes heroicas que, por ventura, uma guerra possa exigir, mas de um mero corpo humano vulnerável, débil e insignificante.

Em termos de representação, essa situação de fragilidade, de destrutibilidade e de fraqueza trouxe uma nova postura na forma de se conceber o sujeito humano. Esse estado de impotência se tornou ainda mais profundo após a Segunda Guerra Mundial com os crimes nazistas, com a construção dos campos de extermínio, com os massacres sistemáticos de todos aqueles considerados ilegítimos a uma ideologia autoritária e segregacionista ditada por Adolf Hitler e por seus seguidores. A situação se mostrou muito mais complexa e desesperadora àqueles que tiveram que abandonar seus países para conseguirem viver com um mínimo de dignidade em terras distantes e desconhecidas. O Brasil serviu de refúgio para muitos desses sobreviventes, os quais não só conquistaram uma morada nova como também decidiram registrar, em livros, suas histórias e experiências.

Tais narrativas constituíram aquilo que passou a ser designado de testemunho. O século $X X$, portanto, devido ao acúmulo de violência registrado, fez surgir um novo gênero chamado de relato testemunhal. Esses textos reúnem uma série de características que visam não somente à preservação da memória de uma parcela que se viu desamparada e à mercê dos malogros históricos, mas que objetivam, também, a construção de uma nova ética, um novo ponto de vista para se pensar a humanidade e as relações humanas. Trata-se de relatos que expõem, nas palavras de Benjamin, o "frágil e minúsculo corpo humano", fazendo verter uma história narrada do ponto de vista dos vencidos, e não sob a perspectiva dos vencedores. Em relação a temas, diversos sobreviventes procuraram registrar seus traumas, suas perdas, suas dores, suas desilusões e suas desesperanças. Os testemunhos têm sido importantes, pois, para que se atribuíssem voz e rosto àqueles postos à margem da história.

No Brasil, particularmente, é possível considerar a presença tanto de testemunhos primários (escritos por sobreviventes que apresentam as experiências vividas em "primeira mão") quanto secundários (escritos por não-sobreviventes). Como adverte Márcio Seligmann-Silva (2007), ao se diferenciarem os escritos que enfocam a Shoah produzidos no Brasil a partir de tais conceitos, não se quer qualificar pejorativamente esses últimos, mas tão somente utilizar uma categorização possível dentro dos estudos do fenômeno do testemunho. São categorizações que levam em conta o passado judeu desses sobreviventes, mas, de acordo com o crítico, para se construir um quadro mais amplo da memória da Shoah, seria importante pesquisar se foram produzidos, no país, relatos de sobreviventes de campos de concentração com outros backgrounds, não judaicos, como no caso de sobreviventes políticos, homossexuais, testemunhas de Jeová, ciganos ou membros de outros exércitos que caíram nas mãos dos nazistas.

Dentro da primeira tendência, isto é, dos testemunhos primários, Seligmann-Silva (2007) menciona os seguintes relatos e autores: Quero viver... memórias de um ex-morto (1972), de Joseph Nichthauser, ...E o mundo silenciou (1972), de Ben Abraham, Pesadelos (1976), de Konrad Charmatz, Rumo à vida (1979), de Olga Papadopol, Os lobos (1983), de Alexandre Storch, Lembranças enevoadas (1984), de Sonia Rosenblatt, e A vida e a luta de uma sobrevivente do Holocausto (2005), de Sabina Kustin. Já na segunda tendência citada, têm-se os seguintes títulos e autores: A guerra do Bom Fim (1972), de 
Moacyr Scliar, Contos do imigrante (1956), de Samuel Rawet, Hitler manda lembranças (1984), de Roberto Drummond, A vida secreta dos relógios e outras histórias (1994), de Roney Cytrynowicz, Breve fantasia (1995), de Samuel Reibscheid, e Nas águas do mesmo rio (2005), de Giselda Leirner.

Essas obras constituem aquilo que pode ser chamado de uma literatura da Shoah no Brasil. É possível definir essa expressão como um conjunto de relatos, redigidos no Brasil e em língua portuguesa, que tematizam a experiência de vitimas da Shoah nazista. Não se trata, com isso, de escritores especializados, mas de indivíduos comuns, que não se deixaram intimidar por memórias traumáticas do passado, mas que viram na escrita uma possibilidade de sobrevivência, de superação e de resistência às inúmeras estratégias de esquecimento. É uma produção relativamente pequena em número, pouco conhecida atualmente, mas nem por isso desmerecedora de atenção. Esses livros, principalmente os que se inserem na primeira tendência, carregam um valor histórico, simbólico e ético inestimável, porque narram, do ponto de vista de seus sobreviventes, o inferno nazista com seus campos de concentração fechados, expelindo pelas chaminés, em forma de gases e de fumaça, restos de corpos humanos massacrados pela barbárie e pela ganância.

Joseph Nichthauser é um dos sobreviventes da Shoah nazista. Vítima da fome, das perdas irreparáveis, das doenças e dos trabalhos forçados, viu na escrita um meio para encontrar e atribuir um sentido para a sua vida. Em 1972, publica Quero viver... memórias de um ex-morto, em que narra sua passagem e suas experiências por diversos campos de concentração na Europa durante a Segunda Guerra Mundial. Esse livro, de acordo com alguns estudiosos, é um dos mais bem escritos da literatura de sobreviventes da Shoah produzida no Brasil. Em 2003, o autor lança $A$ morte de um carrasco, obra dividida em 18 seções, nas quais Nichthauser narra sua experiência em Auschwitz e diversas outras experiência de sobrevivência, até desembarcar no Brasil, em setembro de 1955, quando inicia a sua vida profissional como engenheiro químico, fator que lhe redeu, em suas palavras, seu primeiro salário.

Os 18 capítulos que constituem essa obra narram experiências individuais e coletivas de Nichthauser nos campos de concentração. Cada seção trata de um assunto em particular. Em alguns capítulos, o autor apresenta as brutalidades cometidas pelos soldados nazistas contra os judeus e demais prisioneiros; em outros, ele fala sobre a fé das vítimas à luz do holocausto; em outros, ainda, sobre o seu processo de libertação ao final da guerra; por fim, nas ultimas seções, discorre sobre sua chegada e vida no Brasil. Embora aparentemente díspares no que concerne aos temas, os assuntos se articulam e permitem uma visão mais abrangente da condição humana em situações limites. Ademais, A morte de um carrasco é um relato em que se percebe a presença de diferentes gêneros: relatos históricos, cartas e crônicas, principalmente.

A violência e a opressão exercidas sobre os corpos dos judeus nos campos de concentração, a animalização a que eram submetidos, a desautorização de suas crenças religiosas e o próprio processo de imigração foram fatores determinantes para a condenação de todo um povo que, até o início do século $X X$, não sofreu grandes discriminação na Alemanha. A propósito, Ben Abraham (1976) explica que, a partir do século XVIII até a terceira década do século $X X$, os judeus gozavam de pleno direito na Alemanha. Participavam da vida cultural, cientifica e política, tendo destaques nomes como Heine, Mendelsohn, Paul Ehrlich e Einstein. Muitos ocupavam altos postos nas administrações municipais e eram patentes militares, sendo vários deles condecorados por bravura pela Cruz de Ferro (Eiserner Kreuz). Essa liberdade fez com que o índice de assimilação entre judeus-alemães era o mais alto na Europa no período.

A situação começa a mudar após a derrota da Alemanha na Primeira Guerra Mundial. A crise que o país enfrentava encontrou um Adolf Hitler que, na sua doutrina Nacional Socialista, escolheu como bode expiatório os judeus. Em Minha luta, que veio a público em 1925, ele pregava o extermínio dos 
judeus, povo que ele culpava por tudo que havia de errado. Para a propaganda nazista, eles eram ao mesmo tempo capitalistas e comunistas, plutocratas e bolchevistas. A partir de 1928, os isolados pogroms e as esporádicas surras nos judeus tornaram-se cada vez mais comuns. As casas e lojas judias eram pichadas com a cruz suástica e com dizeres antissemitas. A situação piorou após Hitler assumir o poder, em 11 de abril de 1933, quando foram sancionadas leis arianas. Houve congelamento de contas bancárias dos judeus, boicotes econômicos, proibição de ocupação de qualquer função pública. Iniciavam-se as prisões em massa e a condução de judeus para os campos de concentração.

Em 15 de novembro de 1935, foram editadas pelo Reichstag as Leis de Nüremberg. Essas reforçavam os decretos antissemitas, os quais tratavam sobre a pureza do sangue ariano e estipulavam pesadas penas de prisão para os alemães que mantivessem relações matrimoniais ou extramatrimoniais com judeus. Para os arianos casados com judeus antes dessa lei, sobrava uma opção: ou abandonar o cônjuge, declarando nulo o casamento, ou se declarar judeu. Os filhos desses matrimônios eram considerados judeus, salvo quando a mãe ariana fazia uma declaração pública, alegando que seus filos eram bastardos, fruto da relação com seu amante ariano. Como se não bastasse isso, os estabelecimentos judaicos eram confiscados e entregues aos comissários alemães. Aos judeus também ficou proibido entrar nos jardins públicos e assistir a espetáculos nos teatros e cinema.

No verão de 1938, Hitler repatriou todos os judeus para os países de sua origem. Em setembro de 1939, foi criado, na Alemanha, um novo departamento, a RSHA - Reichssicherheitshauptamt, que incluía a Gestapo, a SS, a Kripo e a SD. A tarefa básica desse órgão era se livrar de todos os que podiam armar algum tipo de resistência aos seus atos. A Gestapo e a SS, particularmente, estavam incumbidas da limpeza racial, prendendo e executando todos aqueles que ameaçavam, de alguma forma, seus planos. Eles prendiam, torturavam e matavam qualquer um, principalmente os judeus, considerados "fora da lei". Entre 1939 e 1941, a eliminação dos judeus era feita por "estimulação", ou seja, os alemães encurralavam os judeus nos guetos e, por falta de comida, medicamentos, roupas e higiene, o processo biológico entrava em enfraquecimento e acelerava a desintegração física. Muitos, porém, foram mortos em campos de concentração construídos basicamente para fins de extermínio em massa. Conforme Abraham (1976, p. 81),

[o]s demônios do século $X X$ criaram os campos de extermínio: Treblinka, Belzec, Majdanek, Sabibor, Auschwitz, Chelmno, Stutthof, Janov - onde milhões de judeus morreram nas câmaras de gás, sem discriminação de sexo ou idade. As "fábricas da morte" atingiram seu auge em 1942.

É justamente em 1942 que Joseph Nichthauser ingressa no campo de concentração em Auschwitz. Naquele espaço repleto de violência, de tristeza e de selvageria, ele questiona a sua própria humanidade: "[q]uanto tempo seremos ainda seres humanos?" (NICHTHAUSER, 2003, p. 61). A pergunta denota que a situação não é passageira e nem um pouco amena, mas crítica e preocupante. Em outra passagem, o autor afirma: "[a] desumanização maciça e sistemática fazia deles [dos prisioneiros] um stück, uma peça que não era mais que o número de matrícula tatuado" (NICHTHAUSER, 2003, p. 26). O objetivo dos nazistas era justamente igualar todos os judeus numa mesma categoria; nesse caso, o intuito era anular a condição humana desses indivíduos e reduzi-los à condição de objeto. No momento em que a integridade física e emocional do sujeito fica abalada e ele perde os pilares que dão sustentação à sua vontade de viver, ele é facilmente coagido e conduzido às câmaras de gás.

Em A morte de um carrasco, há várias passagens em que o autor faz referência à tortura - e ao seu correlato, a dor física - como estratégia de dissolução da condição humana. As relações entre tortura e dor, a propósito, foram exemplarmente desenvolvidas por Elaine Scarry em seu famoso livro The Body in Pain: The Making and Unmaking of the World. Segundo a pesquisadora (1985, p. 27), a 
tortura é, em si mesma, uma forma de linguagem que expressa, em certo grau e medida, a experiência de dor infligida no corpo de uma vítima e é também um elemento que concede certa visibilidade sobre a estrutura e a enormidade daquilo que é geralmente privado e incomunicável por estar contido dentro dos limites do corpo do torturado. No fragmento abaixo extraído do livro de Nichthauser, observa-se que há uma série de itens aludidos pelo autor que anunciam as dimensões da tortura e da dor física:

Alguns blocos tornaram-se rapidamente os mais sinistros: nas celas-masmorras do Bloco 11 , os SS da Politische abteilung (polícia política), interrogavam e torturavam, utilizando o suplício da balança (o prisioneiro era dependurado pelos pés, cabeça e braços pendentes e um outro o balançava induzindo a desmaios, vômitos e mal-estar profundos), que fazia explodir os órgãos genitais; seu subsolo vivenciou os primeiros gazeamentos, enquanto, diante do muro negro construídos na extremidade do pátio entre os Blocos $10 \mathrm{e}$ 11, foram fuzilados milhares de vítimas designadas pela Gestapo, sobretudo os oficiais poloneses e, entre os soviéticos, os "comissários políticos". No Bloco 10, praticava-se, desde o princípio, experiências médicas in vivo. (NICHTHAUSER, 2003, p. 23)

Nichthauser afirma a existência de interrogatórios e de torturas em blocos do campo de concentração. Nessa descrição, o autor faz uso de alguns substantivos e adjetivos que merecem destaque pela importância que assumem para expressar a dimensão dos suplícios humanos. Alguns desses vocábulos seriam: "celas-masmorras", "balança", "subsolo", "gazeamentos", "muro negro" e "extremidade do pátio". Esses objetos ou espaços, dado o contexto, ganham valor semântico específico, pois imprimem às torturas e aos interrogatórios uma dimensão de crueldade ainda mais acentuada. É como se eles desempenhassem um papel homólogo ao de uma arma de fogo. Nesse sentido, nas palavras de Scarry (1985, p. 27-28), a "tortura é um processo que não apenas converte, mas que também anuncia a conversão de todos os aspectos concebíveis do evento e do ambiente em um agente de dor"1. Ou seja, pode-se fazer uma projeção da intensidade da dor a partir dos elementos que estão envolvidos no ato de tortura.

Um segundo aspecto que merece destaque nessa passagem e que se filia à tortura diz respeito aos interrogatórios. Segundo Scarry (1985, p. 28), a tortura implica a existência de dois componentes: um ato físico, quando a dor é infligida no corpo da vítima, e um ato verbal, quando se realiza o interrogatório. A primeira dificilmente ocorre sem o segundo. A ideia perpassada de que a necessidade da informação é uma das razões que justifica a crueldade física não teria muitos fundamentos. De acordo com a autora, as questões dirigidas às vitimas, por mais irrelevantes que possam ser, são anunciadas como se elas motivassem a crueldade, como se as respostas a elas fossem cruciais. Nesse sentido, os interrogatórios não se situam no lado de fora de uma sessão de tortura; eles fazem parte da estrutura da violência imposta e está lá em virtude de sua íntima conexão e interação com a dor física. A dor física, devido à violência infligida ao corpo, e a dor moral, devido à culpa pelas confissões, desempenhariam papel fundamental de desintegração da vítima.

Convém acrescentar que os interrogatórios contam com um componente adicional: os gritos proferidos pelos interrogadores, que, além de intimidarem as suas vítimas, funcionam, igualmente, como armas de fogo, com o intuito de lhes causarem dor. Com essa estratégia de atemorização, o carrasco estaria invadindo o espaço do outro, o corpo da vítima, extraindo-lhe confissões que, em certa instância, se converterão em veículos de autocondenação. Ao forçar uma confissão, como geralmente acontece, o torturador está produzindo um efeito de aniquilamento no corpo da vítima, pois, nesse caso, o próprio corpo e a própria voz da vítima se voltariam contra si mesmo. Em outros termos, o próprio corpo da vítima se transformaria num instrumento de autopunição. Conforme Scarry (1985, p. 46), "assim como as palavras de um se tornaram

\footnotetext{
1 No original: "torture is a process which not only converts but announces the conversion of every conceivable aspects of the event and the environment into an agent of pain".
} 
uma arma, as palavras do outro são expressão de dor, em muitos casos, dizendo ao torturador nada além do quanto o prisioneiro está sofrendo"”2.

Ainda quanto aos interrogatórios, como explica Scarry (1985, p. 37), eles são cruciais para o regime opressor. Dentro dos limites da tortura, o algoz não dispõe de nada, exceto da ausência. E, para compensar tal ausência e para marcar uma distância entre torturador e torturado, o primeiro decorre ao aspecto verbal, no caso, o interrogatório e suas artimanhas. Nesse caso, a autora propõe a seguinte fórmula: quanto mais a dor do prisioneiro, maior é o mundo do torturador; quanto maior é o mundo do torturador, maior é a ausência de mundo do prisioneiro. Se essa ordem de ideias é congruente - e acredita-se que seja -, pode-se dizer que 0 interrogatório foi um poderoso artifício utilizado pelos nazistas tanto para cobrir suas inconsistências ideológicas quanto para anular a humanidade dos judeus.

Outro detalhe que chama a atenção nesse trecho do livro diz respeito às "experiências médicas in vivo". Com essas práticas, os minúsculos e frágeis corpos dos judeus são reduzidos a duas instâncias possíveis: eles são igualados a animais, a cobaias, ou são equiparados a objetos descartáveis, isentos de qualquer traço de humanidade. Tais experiências médicas apresentam uma dimensão homóloga a uma sessão de tortura. Considerando-se que, nessas circunstâncias, qualquer objeto pode adquirir o valor simbólico de uma arma de fogo, que pode assustar, provocar dor ou matar, os prováveis apetrechos cirúrgicos utilizados funcionariam, da mesma forma, como instrumentos de tortura, pois não estariam sendo usados para reparar o corpo da vítima, mas para the infligir dor, medo, pânico. Esses detalhes aparecem de modo evidente em outro trecho de $A$ morte de um carrasco em que Nichthauser qualifica as experiências médicas in vivo como "mutiladoras" e "dolorosas" (NICHTHAUSER, 2003, p. 30).

\footnotetext{
2 No original: "Just as the words of the one have become a weapon, so the words of the other are an expression of pain, in many cases telling the torturer nothing except how badly the prisoner hurts".
}

A propósito da equiparação dos judeus a animais, em $A$ morte de um carrasco, há diversas passagens em que soldados nazistas se dirigem aos judeus, chamando-os de "porcos" e "cachorros". O fragmento a seguir foi extraído do capítulo 11, "Castigos sem crime", em que Nichthauser narra uma experiência pessoal de pânico. Se algum prisioneiro cometesse alguma falta, ele seria punido com algum tipo de agressão física; e a natureza desse castigo variava conforme o tipo de delito praticado: alguns sofriam privações; outros eram espancados; outros, ainda, eram enforcados ou fuzilados. Em maio de 1944, ocasião em que Nichthauser trabalhava num imenso complexo químico, um soldado o encontra dormindo nas dependências da fábrica, motivo que Ihe rende uma séria advertência:

- "Em pé, cachorro!" Alguém estava tocando minha coxa com o pé; eu estava dormindo sentado, encostado nos botijões de acetileno e oxigênio.

"Em pé, cachorro!"

Levantei-me, instintivamente, e coloquei-me em posição de sentido.

$\mathrm{Na}$ minha frente, com um caderninho na mão, estava um dos mestres da nossa área, olhando-me com um sorriso sarcástico.

"Deixa eu ver o seu número, seu porco!" Ele anotou no caderninho e tornou a olhar meu antebraço esquerdo, onde estava o número tatuado: 184.465. (NICHTHAUSER, 2003, p. 96-97)

Há pelo menos cinco situações nesse excerto que visam a destacar uma suposta ideia de inferioridade de Nichthauser: o fato de ele ter sido chamado de "cachorro", o fato de ele ter sido tocado com o pé do soldado, o fato de esse último olhá-lo com um sorriso sarcástico, o fato de ter sido chamado de "porco" e o fato de ter sido reduzido a um número. Cães e porcos são animais caracterizados pela sujeira, logo, ao ser chamado de "cachorro" e de "porco", o soldado tenta reforçar em Nichthauser - e, por extensão, aos judeus - a suposta ideia de impureza da raça. Se se trata de uma raça impura, na visão dos nazistas, ela deve ser exterminada. $O$ fato de o soldado ter tocado o prisioneiro com os pés (e 
não com as mãos) reforça essa ideia: se os judeus são sujos, impuros, eles devem ser tocados com os pés. O gesto também define a frieza no tratamento aos judeus. Ademais, o fato de o soldado ter desprendido um olhar sarcástico em direção a Nichthauser define uma ideia de dominação e uma posição de superioridade do agente. Por fim, a numeração que identifica Nichthauser é a própria coisificação do sujeito.

Essas situações, que ilustram processos de degradação da condição humana, podem servir de exemplos para se pensar a construção da identidade dos sujeitos em campos de concentração. Se, numa certa concepção, a identidade pode ser definida como a imagem que o indivíduo constrói e adquire ao longo de sua existência referente a si mesmo, para, inclusive, ser percebida pelo outro, então, "[n]um contexto em que a condição humana se pauta em valores degradantes, o indivíduo vê com perplexidade sua constituição enquanto ser humano $e$, por extensão, é incapaz de projetar a sua identidade em função do outro" (HAISKI, 2013, p. 104). Não se trata de alguém que constrói sua identidade pautado em valores afirmativos, mas de um sujeito que perdeu seu nome, que foi reduzido simplesmente a um número e que foi rebaixado a uma condição muito próxima a de um animal.

O objetivo dos nazistas era justamente encontrar meios para humilhar os judeus a ponto de se sentirem insignificantes. Investia-se em diferentes estratégias de degradação para torná-los impotentes frente ao sistema. Isso fazia com que aceitassem a sua própria eliminação e extermínio. Assim, o terror que constituiu a Shoah foi possível graças à dissolução do sujeito na sociedade. A frieza, a falta de amor e a indiferença que caracterizavam as relações humanas nos campos de concentração culminaram no holocausto, justificando, de certa forma, os crimes nazistas. Nesse sentido, é plausível a afirmação de Theodor Adorno (1994), segundo o qual o extermínio em massa de judeus em campos de concentração não foi um acontecimento isolado, mas algo coerente com o desenvolvimento de uma sociedade reificada.
Esses apontamentos prestam-se para a análise do fragmento a seguir. Nele, Nichthauser projeta uma reflexão sobre a condição humana numa circunstância crítica da sua história. Trata-se do momento em que se aproximava o final da guerra. Isso se deu a partir do segundo semestre de 1944. A batalha na Rússia estava perdida; a África do Norte já tinha sido libertada; o desembarque das forças aliadas na Normandia já era fato. Com isso, o nazismo tentava, desesperadamente, apagar os rastros de sua máquina genocida. Como era impossível eliminar quase 300 mil prisioneiros de diferentes campos de concentração, surgiu a ideia de transportá-los de um campo para outro mais distante. A ideia era justamente aproveitar a debilidade física e o estado emocional para que não houvesse reações e para que grande parte do contingente padecesse. Em suas notas, Nichthauser observa:

Quando alguém era obrigado a se despir e receber um paletó, uma camisa, uma cueca, uma calça e um par de sapatos, que representavam o uniforme regulamentar do prisioneiro, tudo listrado de azul e branco, cessava a vontade individual. Havia já uma transformação brutal no comportamento e no pensamento do prisioneiro.

Em seguida, o trabalho exigido pela administração era muito pesado, nunca menos de doze horas diárias. E, a partir de 1944, o repouso dominical foi suprimido, não se permitindo, assim, quase nenhuma possibilidade de um pensamento mais íntimo, do descanso da mente e da alma.

Obedecer era, obviamente, uma regra, caso contrário, os espancamentos aconteciam.

Os presos, então, transformavam-se em simples robôs, programados para obedecer às ordens dos escassos guardas SS, mas, acima de tudo, de seus chefes de grupo, kapos e membros da administração interna que, mesmo sendo também prisioneiros, executavam fervorosamente todas as ordens recebidas dos SS. (NICHTHAUSER, 2003, p. 103)

Convém destacar desse fragmento que a violação da humanidade dos judeus inicia-se pela exigência de uso de uniformes listrados. Esses trajes não só tolhiam a individualidade de cada um como também imprimiam aos prisioneiros a marca da suposta inferioridade. A supressão dos descansos e as fortes exigências nos campos de trabalho esgotavam física e espiritualmente cada um dos 
presos, subtraindo-lhes o desejo de revoltas, rebeliões e resistências. A reificação era evidente: os prisioneiros convertiam-se em meros robôs, aptos a executarem ordens e a prestarem obediência. Há, nesse conjunto de fatores, as condições ideias para o extermínio sistemático de todos os presos: anulação das individualidades, conversão de sujeitos em autômatos, senso de obediência e, com isso, a perda da vontade de viver.

Para que a dissolução da natureza humana dos judeus se cumprisse de modo ainda mais satisfatório, era preciso que os nazistas investissem em projetos que atingissem os muitos âmbitos de expressão dessa comunidade. Nesse sentido, a censura às manifestações religiosas era bastante comum. Em A morte de um carrasco, há diferentes capítulos e várias passagens em que o autor alude ao aspecto religioso como estratégia para os judeus se manterem esperançosos em relação ao presente e em relação a seu futuro e, também, em certa instância, para continuarem vivos. O capítulo 2 é a reprodução de uma carta que Nichthauser escreveu ao Padre Maximilian Kolbe em maio de 1975. Nessa seção, o autor descreve várias situações de postas entre a vida e a morte dos judeus: fome, frio, intolerâncias, humilhações, espancamentos, assassinatos. No entanto, ele pondera: "[o] martírio cruel da cela da fome foi enfrentado com a mais absoluta pureza. Pureza na fé, diante da maldade extrema; pureza de um espírito inquebrantável; pureza do sacrifício pelo irmão..." (NICHTHAUSER, 2003, p. 36).

É justamente esse ponto - o sacrifício pelo irmão - que Nichthauser quer relatar para exaltar a humanidade do Padre Kolbe. Em julho de 1941, um prisioneiro que não fora recuperado faz com que outros dez paguem com a vida. Dentre os escolhidos, estava um sargento do exército polonês, que se desespera por possuir mulher e filhos. Frente a essa situação e tomado por compaixão, Padre Maximilian Kolbe se oferece para ser morto em seu lugar. A situação é considerada exemplar para Nichthauser: "[c]omo esse cara podia se doar tanto, doando sua própria vida por um outro sujeito que ele nunca viu?"
(NICHTHAUSER, 2003, p. 37). A atitude de Kolbe desloca a perspectiva em que muitos judeus se baseavam. Seu exemplo os havia levado a outro lugar, ao infinito, fazendo-os esquecer das angústias e das incertezas do cotidiano. Se, nos termos do autor, eles estavam descendo ao nível dos lobos, ao último degrau da escala, a postura de Kolbe se traduz como uma semente de esperança dentro de um cenário tão monstruoso.

Ainda nessa perspectiva, tem-se o capítulo 8, dedicado a Edith Stein. Devota de Santa Teresa de Ávila, converteu-se em 1922, com 30 anos de idade. Em 1933, o diretor espiritual Beneditino Ihe deu a permissão para entrar na Comunidade das Carmelitas Descalças, em Colônia-Lidenthal. Em abril do ano seguinte, adotou o nome religioso de Teresa Benedicta da Cruz e, em 1935, fez seus votos finais. Em 31 de dezembro de 1938, ela secretamente cruzou a fronteira para a Holanda, sendo recebida pelas Carmelitas de Echt. Nessa clausura, ela escreveu seu último trabalho, $A$ ciência da cruz. Dedicou a sua vida ao próximo, ao perseguido e ao sofredor e, pela influência que exerceu, foi levada do Carmelo de Echt, em 2 de agosto de 1942, num trem de gado, até o campo de extermínio de Auschwitz. Morreu numa câmara de gás sete dias, em 9 de agosto de 1942. Na perspectiva de Nichthauser, Stein fora uma fonte inspiradora para todos aqueles que devotaram sua vida a ajudar os fracos e humilhados.

O capítulo 7, "A fé à luz do holocausto", é uma projeção dos pensamentos de Nichthauser a propósito da fé nos campos de concentração. O autor relata que, desde abril de 1940, nos primeiros dias da existência dos campos de extermínio, uma frase era proferida insistentemente entre os prisioneiros: "Deus morreu nas câmaras de gás" (Nichthauser, 2003, p. 71). Essa ideia é rechaçada por Nichthauser que a considera absurda e sem sentido:

Como não crer, quando tudo o que nos cerca não é uma obra que surgiu por mero acaso ou sem finalidade e objetivo, determinado, com certeza, por uma vontade cósmica. Poderiam surgir milhares de indagações. Por quê? É evidente que jamais teremos respostas. [...] Sem dúvida, esta falta de conhecimento, de sabedoria e de conclusões definitivas não nos 
fazem diminuir a crença e a fé em Deus TodoPoderoso. [...] Não aceitar é um pensamento negativo que não nos conduz a nada, salvo para uma trilha de um ateísmo insignificante, um vazio, um vácuo, um zero na alma infinita. [...] Auschwitz era um inferno. E mesmo lá havia fé e esperança. Havia preces, muito cedo, de madrugada ainda. (NICHTHAUSER, 2003, p. 72, 73, 74 e 75)

Essas são algumas passagens da obra de Nichthauser em que a crença, a fé e a inspiração são elementos importantes tanto de sobrevivência quanto de resistência. No primeiro caso, os judeus encontravam, em pessoas exemplares - como Kolbe e Stein -, algum otimismo e esperança para lutarem contra a morte que se fazia onipresente. Num mundo marcado pela brutalidade humana, as ações de alguns homens e de algumas mulheres podem ser decisivas para o dia de amanhã. Ademais, a confiança em Deus os colocava num patamar superior, próximo ao criador, ficando, assim, bem distantes do nível a que eram rebaixados. É justamente essa aproximação com Deus que os conduzia a uma espécie de purificação e, portanto, de (auto)aceitação. Trata-se de formas de evasão ou de consolo em relação à situação em que se encontram. Com isso, mesmo não havendo respostas para certas indagações, eram as crenças que os sustentavam.

A crença no poder divino, aliás, traduzida na observância tanto a homens e a mulheres exemplares quanto a determinadas atitudes, converte-se em elemento de resistência. Isso porque a religião é um fator agregador de energias e de forças que podem se colocar contra a ordem autoritária instituída. Nichthauser, ao fazer referência à postura dos nazistas em relação à religião, é enfático e imperativo: "[r]ezar era proibido. Possivelmente os nazistas supunham que rezar sustentava moralmente as pessoas e, em especial, os judeus. A religiosidade era mantida sem incentivos: cada um orava como queria" (NICHTHAUSER, 2003, p. 43). Assim, se os nazistas tinham a capacidade de subtrair dos judeus e dos demais prisioneiros aquilo que thes era essencial, a religião podia devolver-lhes um motivo para resistirem.
A religião ajudou a manter vivos muitos prisioneiros nos campos de concentração. Muitos haviam sido mortos, evidentemente, mas muitos haviam sobrevivido até abril de 1945, quando tropas americanas chegam e libertam os que sobraram dos massacres nazistas. Porém, após a sua libertação, surge outro dilema: permanecer em sua terra natal ou reconstruir a vida em terras distantes? Se elegessem a primeira opção, além de terem que conviver com os monumentos de barbárie que os traumatizaram impiedosamente, teriam que conviver com a ausência de seus familiares. Se escolhessem partir para outro país, enfrentariam as incertezas do desconhecido. Conforme declaração de Joseph, “[e]stávamos completamente desamparados, desnorteados, buscando desesperadamente um objetivo, um sentido para a vida futura" (NICHTHAUSER, 2003, p. 151).

Em princípio, havia três principais países dispostos a acolher esses indivíduos: Suíça, França e Suécia. Os grupos de sobreviventes se dividiram. Joseph e outras crianças oriundas do campo de Buchenwald foram inicialmente para um orfanato, em Ecouis, na França. Nesse país, conseguiu encontrar a irmã Fela que sobreviveu em outro campo de concentração. Tentou retomar a vida na Europa, mas foi convocado pelo governo francês a lutar na Argélia. Contrário a essa ideia, com a ajuda da irmã, consegue embarcar para o Brasil. Ele chega ao Rio de Janeiro em 21 de setembro de 1955. Algum tempo depois, começa a trabalhar como engenheiro químico em uma fábrica e ganha seu primeiro salário. Aos poucos, vence a barreira do idioma e conquista vários amigos.

Apesar de o Brasil ter acolhido Nichthauser e de ter Ihe dado condições de vida mais humanas, não se pode ignorar o fato de ele ter saído da Europa devido a um contexto de violência extrema. Ou seja, ele não abandonou sua terra natal por desejo próprio, mas motivado por circunstâncias históricas adversas. De acordo com Berta Waldman (2009, p. 3), partindo das reflexões do sociólogo argelino Abdelmalek Sayad, a imigração é "um fato social completo" que implica a existência tanto do "emigrante", que deixa o seu país de origem, quanto do "imigrante", que chega 
a terras estrangeiras. O paradoxo, nesse caso, consistiria no fato de ambos - emigrante e imigrante serem as mesmas pessoas. O imigrante nasce no momento em que o país a que ele chega o acolhe. Nessa ocasião, pondera Waldeman, esse acolhimento implica a mutilação de uma história, um exercício de poder interessado em apagar as diferenças culturais.

Os diversos grupos de imigrantes que se instalaram no Brasil, no final do século XIX e início do século $X X$, vieram motivados por razões históricas específicas formuladas em seus países de origem. Foi assim com italianos, alemães, poloneses, russos, japoneses e, em menos grupo, os judeus. Ao chegarem ao país estrangeiro, esses indivíduos enfrentavam, conscientemente ou não, mecanismos repressivos de Estado. Em muitos casos, tratava-se de mecanismos dedicados, entre outros, à obstrução de circulação de ideias vindas de fora, ao impedimento do uso da sua língua do país de origem e à proibição de publicação de artigos em jornais e revistas com opiniões diversas. Eram estratégias de preservação da hegemonia nacional já que tais mecanismos determinavam que opções de um grupo de imigrantes poderiam prevalecer dentro de um período histórico e de um lugar específicos. Esse tratamento diferenciado que recebiam corroboravam processos diversos de desumanização.

Por fim, é importante destacar a centralidade do capítulo 13 intitulado "A morte de um carrasco". Essa seção dá título à obra e, por isso mesmo, tem uma relevância específica para o texto. Ela trata sobre os instantes imediatamente posteriores à chegada das tropas americanas no campo de Buchenwald em abril de 1945. A chegada dos americanos é um prenúncio do fim da guerra e a consequente libertação dos prisioneiros dos campos de concentração. Depois de conquistarem a liberdade, Joseph e seus companheiros estão ciosos por aproveitarem a vida, mas também estão sedentos por vingança. O desejo deles é caçar e matar soldados nazistas que, agora, estão desamparados. Joseph, apesar de tudo o que sofreu, principalmente pelo fato de ter perdido a família e o seu irmão, David, dez dias antes da libertação, tem uma postura serena: "[e]u não tenho medo de matar um SS. Nada disso. Isso seria até fácil. Mas não tenho certeza se esse tipo de procedimento é justo" (NICHTHAUSER, 2003, p. 120).

Curiosamente, a algumas dezenas de metros do campo de onde foi liberto, Joseph avista um soldado das tropas nazistas no chão, sangrado e muito ferido. Num primeiro momento, Joseph julga que ele está morto; logo em seguida, percebe nele alguns sinais vitais: "[f]rente a frente, um representante de um povo assassinado e um carrasco" (NICHTHAUSER, 2003, p. 123). Joseph armou-se com um pedaço de pau, planejou os golpes que tirariam os últimos minutos de vida do soldado, mas se lembrou do Rabino Avigdor, que, certa vez, havia lhe dito: "Não matarás". A partir disso, ele toma a decisão de não acabar com a vida do soldado. Esboça-se, com tudo isso, uma situação sem explicação a Joseph: "[b]em que eu gostaria de saber por que eu o salvei. Por quê? Pode me responder?" (NICHTHAUSER, 2003, p. 128).

A reação de Joseph ilustra a maneira como ele reagiu às adversidades de sua vida, a qual foi dizimada pela brutalidade de uma ideologia absurda e sem limites. Com isso, seria possível esperar dele sentimentos de amargura, tristeza, rancor ou sede de vingança. Porém, frente aos grandes desafios e provações por que passou ao longo de toda a sua vida, a sua conduta foi surpreendente e exemplar. Pouco a pouco, foi trazendo de volta parte do sentido que sua vida tivera antes dos campos de concentração, semeando compreensão, sensatez e solidariedade. Nas mãos dos carrascos, o corpo de Nichthauser tornou-se minúsculo e frágil, mas sua alma manteve a dimensão de quem sempre soube acolher o outro e ser capaz de reconhecer e restaurar a dignidade humana. 


\section{Referências}

ABRAHAM, Ben. Holocausto: o massacre de 6 milhões. 29. ed. São Paulo: WG Comunicações e Produções, 1976. 160p.

ADORNO, Theodor. Educação após Auschwitz. In: COHN, Gabriel (Org.). Theodor W. Adorno: sociologia. Trad. Flávio R. Kothe, Aldo Onesti e Amélia Cohn. 2. ed. São Paulo: Ática, 1994. p. 3345.

BENJAMIN, Walter. Experiência e pobreza. In: Magia e técnica, arte e política. Vol. I. Trad. Sérgio Paulo Rouanet. 7. ed. São Paulo: Brasiliense, 1985. p. 114-119.

HAISKI, Vanderléia de Andrade. Trauma, memória e narrativa em The Pawnbroker, de Edward Lewis Wallant, e Quero viver... memórias de um exmorto, de Joseph Nichthauser: comparações e intersecções. 2013. 139f. Dissertação (Mestrado de Letras) - Universidade Regional Integrada do Alto Uruguai e das Missões, Frederico Westphalen, 2013.

NICHTHAUSER, Joseph. A morte de um carrasco. Belo Horizonte: Saitec Ed., 2003. 202p.

SCARRY, Elaine. The Structure of Torture: The Conversion of Real Pain into the Fiction of Power. In: . The Body in Pain: The Making and Unmaking of the World. New York, Oxford: Oxford University Press, 1985. p. 27-59.

SELIGMANN-SILVA, Márcio. Literatura da Shoah no Brasil. Arquivo Maaravi, Belo Horizonte, n. 1, v. 1, s. p., out. 2007.

WALDMAN, Berta. Notes Concerning Jewish Identity in Brazil: From Word to Image. In: FOSTER, David William (Ed.). Latin American Jewish Cultural Production. Nashville: Vanderbilt University Press, 2009. p. 3-23.

\section{COMO CITAR ESSE ARTIGO}

CALEGARI, Lizandro Carlos. A literatura da Shoah no Brasil: o frágil corpo humano em A morte de um carrasco, de Joseph Nichthauser. Signo, Santa Cruz do Sul, v. 45, n. 82, jan. 2020. ISSN 1982-2014. Disponível em: <https://online.unisc.br/seer/index.php/signo/article/view/14309>.

Acesso em: doi:https://doi.org/10.17058/signo.v45i82.14309. 